\title{
OPEN Release characteristics of Pb and BETX from in situ oil shale transformation on groundwater environment
}

\begin{abstract}
Han Wang ${ }^{1,2,3}$, Wenjing Zhang ${ }^{1,3}$, Shuwei Qiu ${ }^{4,5,6 \bowtie}$ \& Xiujuan Liang ${ }^{1,2,3 凶}$
Oil shale has received attention as an alternative energy source to petroleum because of its abundant reserves. Exploitation of oil shale can be divided into two types: ex situ and in situ exploitation. In situ transformation has been favoured because of its various advantages. Heating of oil shale leads to the production of oil and gas. To explore the influence of solid residue after pyrolysis of oil shale on the groundwater environment, we performed ultrapure water-rock interaction experiments. The results showed that $\mathrm{Pb}$ tended to accumulate in solid residues during pyrolysis. Additionally, the $\mathrm{Pb}$ concentration goes up in the immersion solution over time and as the pyrolysis temperature increased. In contrast, when we measured the soaking data of benzene series, the concentrations of benzene and toluene produced at temperatures over $350^{\circ} \mathrm{C}$ were highest in the four oil shale pyrolysis samples after pyrolysis. The water-rock interaction experiment for $\mathbf{3 0}$ days led to benzene and toluene concentrations that were $10^{4}$ and 1070 -fold over the limit of China's standards for groundwater quality. Over time, the content of benzene series was attenuated via biological actions. The results show that in situ oil shale mining can lead to continuous pollution in the groundwater environment.
\end{abstract}

Because of the rapidly increasing demand for oil, conventional petroleum resources will eventually be depleted. Thus, unconventional petroleum resources must be developed and utilised ${ }^{1}$. Oil shale is a combustible sedimentary rock containing organic material, fine bedding, and high ash and solid combustible mineral contents and can be considered as an alternative energy source to crude oil ${ }^{2,3}$. The oil content of oil shale is more than $3.5 \%$. Shale oil, dry distillation gas, and semi-coke shale can be obtained by low-temperature dry distillation ${ }^{4}$. The properties of shale oil are very similar to those of petroleum ${ }^{5}$; therefore, existing equipment can be used for oil extraction. The organic matter content generally reaches $40 \%$ of the total mass of oil shale ${ }^{6}$, whereas the inorganic matter content (minerals) is higher (generally $>60 \%$ ). Organic components include organic $\mathrm{C}, \mathrm{H}, \mathrm{O}$, $\mathrm{N}$, and $\mathrm{S}$. Inorganic components mainly include quartz, muscovite, kaolinite, calcite, and carbonate. In some areas, oil shale contains small amounts of diamond, iron ore, and $\mathrm{S}, \mathrm{Ti}, \mathrm{Cr}, \mathrm{Ni}$, and other elements. The organic matter of oil shale mainly includes kerogen and bitumen ${ }^{7}$. The bitumen content of Chinese oil shale is generally $\sim 1 \%$. Organic matter is the main source of shale oil and shale gas during oil shale pyrolysis. Shale oil (calculated based on in situ oil shale) accounts for $\sim 400$ billion tons of oil worldwide, which is higher than that of traditional crude oil that accounts for $>300$ billion tons of oil worldwide 8 .

Oil shale pyrolysis technology can be divided into traditional surface retorting technology and underground in situ transformation technology ${ }^{9-11}$. Oil shale surface retorting leads to several environmental problems such as water-air pollution and waste residue stacking, restricting the large-scale use of oil shale resources ${ }^{12}$. Because of the disadvantages of large-scale investments, high pollution, and high cost of surface retorting technology, various studies of in situ transformation have been conducted worldwide. For example, numerous pilot conversion technologies have been tested on oil shale such as the Shell In Situ Conversion Process, Exxon Mobil

\footnotetext{
${ }^{1}$ Key Laboratory of Groundwater Resources and Environment (Jilin University), Ministry of Education, Changchun 130021, China. ${ }^{2}$ National-Local Joint Engineering Laboratory of In-Situ Conversion, Drilling and Exploitation Technology for Oil Shale, Changchun 130021, Jilin, China. ${ }^{3}$ College of New Energy and Environment, Jilin University, Changchun 130021, China. ${ }^{4}$ School of Water Resources and Environment, Hebei GEO University, Shijiazhuang 050031, China. ${ }^{5}$ Hebei Province Key Laboratory of Sustained Utilization and Development of Water Resources, Shijiazhuang 050031, China. ${ }^{6}$ Hebei Province Collaborative Innovation Center for Sustainable Utilization of Water Resources and Optimization of Industrial Structure, Shijiazhuang 050031, China. ${ }^{\square}$ email: qqwenzi6725@163.com; xjliang@jlu.edu.cn
} 


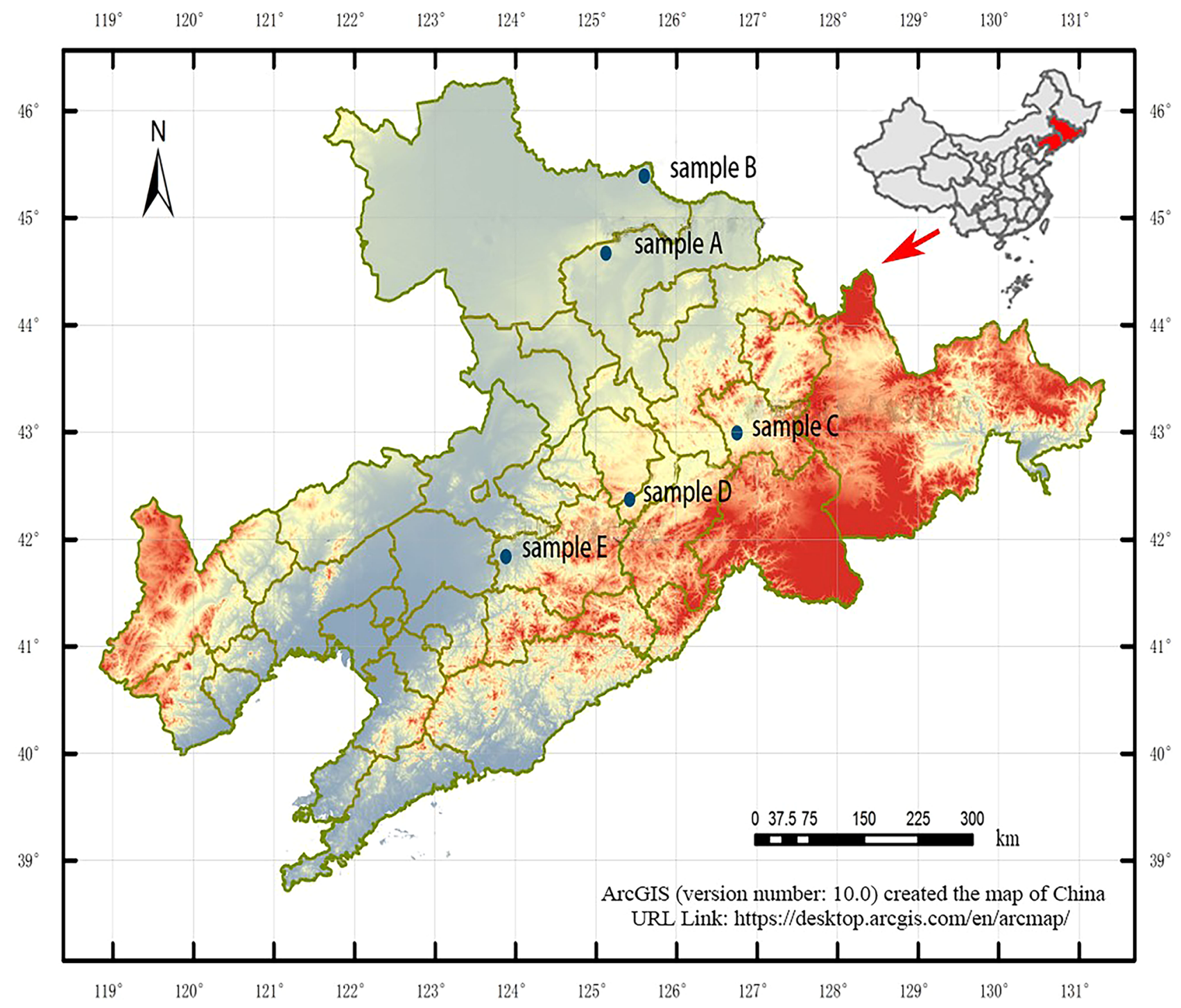

Figure 1. Locations of oil shale sampling points.

Electrofrac technology, and Occidental Modified In Situ technology. In China, technology has been developed by the Zhongcheng Group and Jilin University for in situ conversion experiments on oil shale in the Songliao Basin, which revealed positive results ${ }^{12}$. The technology is mainly used to heat underground oil shale. When the temperature is increased, kerogen in the oil shale releases the shale oil and gas, but also produces large amounts of pollutants ${ }^{13}$. Pollutants remain adsorbed and accumulate in the rock strata for a long period of time; their slow release can cause lasting damage to groundwater and is not conducive to restoration and treatment. Because of the complex composition of pollutants, various pollutants may react chemically with other substances after entering the groundwater or a "synergistic effect" can occur among them, posing a serious threat to the environmental security of groundwater ${ }^{14-18}$.

Few previous studies have focused on the pollution of groundwater caused by in situ oil mining. Hu et al. (2019) reported that in situ oil shale mining aggravates the pollution of groundwater with organic matter and residual oil shale ash ${ }^{19}$. However, the experimental temperature used in the previous study did not reflect the actual oil shale conditions. Numerous studies have focused on the pollution resulting from oil shale heating; when shale is heated to a certain temperature, a series of physical and chemical reactions occurs. As the temperature rises, water begins to evaporate and kerogen decomposes into bitumen, eventually releasing shale oil and gas. With increasing heating temperature, kerogen decomposition increases. During this process, $\mathrm{C}-\mathrm{H}$ bonds break and recombine to form a series of complex organic compounds ${ }^{20-22}$. Kerogen in oil shale undergoes a variety of reactions during pyrolysis ${ }^{23}$, and the presence of inorganic minerals makes the pyrolysis process of oil shale more complex and diverse ${ }^{24}$. The main organic pollutants in groundwater are benzene series (such as benzene, toluene, ethylbenzene, xylene) and phenolic compounds (phenol, naphthol, aniline, pyridine) ${ }^{25}$.

In this study, we selected a representative heavy metal, i.e., $\mathrm{Pb}$, to evaluate the release of heavy metals into the groundwater environment. In contrast to organic contaminants, $\mathrm{Pb}$ cannot be destroyed but can only be relocated. This element is nonessential to the human body, and excessive intake can damage the nervous, skeletal, circulatory, enzymatic, endocrine, and immune systems in humans ${ }^{26}$. Lead is a contaminant that is generally related 
to the mining industry. We also evaluated characteristic organic pollutants (benzene, toluene) in the pyrolysis oil-water immersion solution and residue immersion solution by atomic absorption spectrophotometer ${ }^{25}$. X-ray diffraction (XRD) was performed for five samples from oil shale regions (Fig. 1) to determine the effects of clay minerals on $\mathrm{Pb}$ release and ion precipitation-dissolution equilibrium in the groundwater.

\section{Methods}

Sample and water-rock interaction experiment. Five samples (samples A-E) were collected from five oil shale regions in the Jilin and Liaoning Provinces (Fig. 1) ${ }^{27}$. Prior to the water-rock interaction experiments, we placed the samples in a MXG1200-40S tubular furnace and heated them at $200^{\circ} \mathrm{C}, 350{ }^{\circ} \mathrm{C}$, and $500^{\circ} \mathrm{C}$ for $2 \mathrm{~h}$, generating a solid residue. Shale oil can be divided into distillation fractions for use in petroleum refining processes. Different oil components are produced between 300 and $500{ }^{\circ} \mathrm{C}$; oil and gas are mainly produced between 300 and $475^{\circ} \mathrm{C}^{12,28}$. Based on the division of oil shale pyrolysis process conditions, we selected $0{ }^{\circ} \mathrm{C}$, $200{ }^{\circ} \mathrm{C}, 350^{\circ} \mathrm{C}$, and $500{ }^{\circ} \mathrm{C}$ as the final temperatures ${ }^{29}$. First, a tube furnace was used to heat oil shale. For the water-rock interaction experiment, $50 \mathrm{~g}$ of each of residue was weighed at the same heating temperature in the same area with constant (room) temperature and placed in a 500-mL polyethylene terephthalate bottle with a lid. Ultrapure water was poured into the bottle, and the bottle was closed with the lid. After 0.5, 2, 4, 8, 15, 30, 60, 90, $120,150,180,270$, and 360 days, the $\mathrm{Pb}$ concentration was measured.

Determination of lead content. To ensure that the natural sealing and reducing conditions of the groundwater environment were reflected, one bottle was measured only once. The background value of each ion in water was negligible in this experiment. We used atomic absorption to determine the $\mathrm{Pb}$ content of the immersion solution.

Determination of benzene series concentration. To determine the concentration of benzene series (benzene, toluene) present in the immersion solution, liquid chromatography was carried out using a Shimadzu LC-20AT liquid chromatograph (Kyoto, Japan), SPD-20A ultraviolet-visible detector, CTD-10AS temperature storage tank, and ODS column $(4.6 \mathrm{~mm} \times 250 \mathrm{~cm})$. The chromatographic conditions were as follows: chromatographic column, ODS column $(4.6 \mathrm{~mm} \times 250 \mathrm{~mm})$; mobile phase, $70 \%$ methanol; flow rate of mobile phase, $1.0 \mathrm{~mL} / \mathrm{min}$; injection volume, $50 \mu \mathrm{L}$; column temperature, $40^{\circ} \mathrm{C}$. An appropriate amount of soaking liquid sample was absorbed and filtered through a $0.25-\mu \mathrm{m}$ filter membrane. Next, $50 \mu \mathrm{L}$ was absorbed into the injection needle before testing the stable operation of the instrument injection. The concentrations of benzene and toluene were set to $0.1,1,2,5$ and $10 \mathrm{mg} / \mathrm{L}$, respectively, using a standard solution of benzene and toluene (concentration of $1 \mathrm{mg} / \mathrm{mL}$ ) and ultrapure water.

Clay minerals. XRD can be used to qualitatively describe the compositions of inorganic minerals in oil shale samples before and after the pyrolysis of solid residues ${ }^{30}$. A Shimadzu AA-6000CF atomic absorption spectrophotometer was used to determine the crystal structure parameters, mineral species, and relative kerogen percentage. The samples were dried and crushed to 200 -mesh powders by using a sieve. The experimental conditions were as follows: voltage of $40 \mathrm{kV}$, current of $40 \mathrm{~mA}$, scanning angle $(2 \theta)$ of the copper electrode $(\lambda=1.54184)$ of $5-60^{\circ}$, step length of 0.05 , and scanning speed of $1.0^{\circ} / \mathrm{min}$.

\section{Results and discussion}

Clay minerals. The adsorption of heavy metals by colloidal substances (e.g., clay minerals, inorganic polymers such as water and oxides, and organic polymers such as humus) in natural water affects the conversion of heavy metals in the water environment. In nature, the heavy metal concentration of the aqueous phase is very low. The main enrichment and solid phases are related to colloid adsorption. Oil shale contains large amounts of clay minerals, such as montmorillonite, illite, and kaolinite, which strongly adsorb heavy metals. This characteristic also provides the main pathway of heavy metal transfer from an unsaturated solution to the solid phase. To analyse the mineral characteristics, XRD data (Fig. 2) were automatically extracted and smoothened. According to the XRD patterns, clay minerals (Aimon mixers) were the main inorganic minerals present, followed by quartz and carbonate minerals and a small amount of pyrite. The mineralogical composition of the five samples is shown in Table 1 .

As shown in Table 1 and Fig. 2, all samples mainly contained montmorillonite, illite/montmorillonite, quartz, feldspar, dolomite, calcite, and chlorite. Based on the comparison of the XRD spectra of heated and unheated samples, the peak height of montmorillonite increased with increasing temperature, indicating that dehydration of clay minerals had occurred. When those samples were placed in water, clay minerals recombined with the water and released the adsorbed $\mathrm{Pb}$.

Lead content. Figure 3 shows the change in the $\mathrm{Pb}$ concentration over time for unheated $\left(0{ }^{\circ} \mathrm{C}\right)$ and heated $\left(200{ }^{\circ} \mathrm{C}, 350^{\circ} \mathrm{C}, 500{ }^{\circ} \mathrm{C}\right)$ samples. The $\mathrm{Pb}$ concentration gradually increased over time. The concentrations of $\mathrm{Pb}$ ions in the residues of the immersion solution of all five samples after pyrolysis were higher than that in the original rock ${ }^{31}$. Monitoring of the $\mathrm{pH}$ during this experiment showed that the $\mathrm{pH}$ range was $7-10$. As $\mathrm{Pb}$ exists in various forms of $\mathrm{Pb}^{2+}$ hydroxide in aqueous solution, the $\mathrm{pH}$ also affects the amount of $\mathrm{Pb}$ in aqueous solution. The amount of $\mathrm{Pb}$ in aqueous solution increases under acidic or alkaline conditions.

$\mathrm{Pb}$ concentrations were high in residues and $\mathrm{Pb}$ was easily soluble in water. The overall change in the $\mathrm{Pb}$ concentration was consistent; i.e., it gradually increased over time and with increasing pyrolysis temperatures ${ }^{32,33}$. With increases in the pyrolysis temperature, heavy metals are incorporated into the solid residue. The presence 

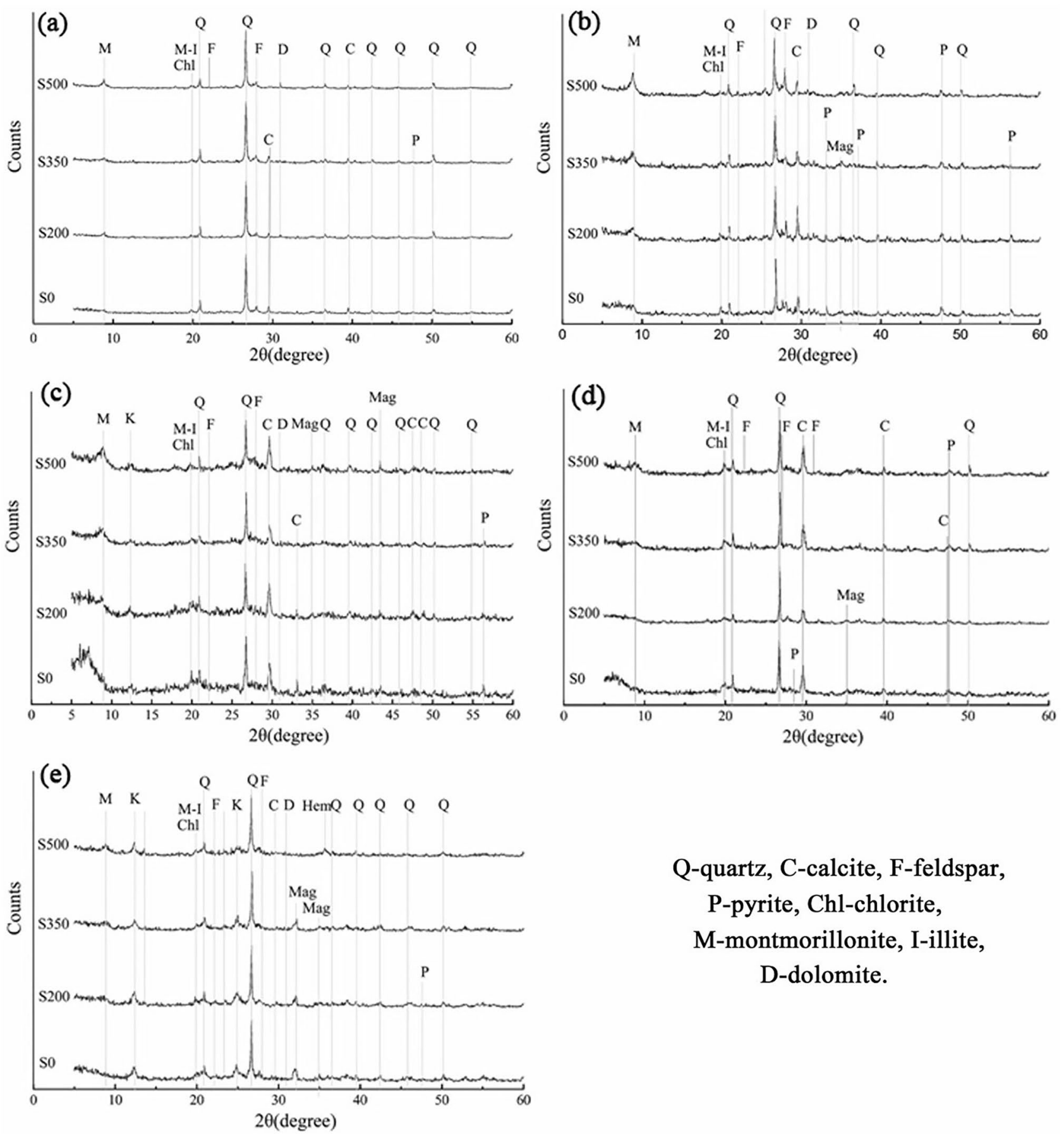

\section{Q-quartz, C-calcite, F-feldspar, P-pyrite, Chl-chlorite, M-montmorillonite, I-illite, D-dolomite.}

Figure 2. X-ray diffraction data of five samples.

of heavy metals in oil shale is important factor in its leaching behaviour. Studies have shown that heavy metal elements in oil shale exist in various states ${ }^{34,35}$ : water-soluble state, ion-exchange state, carbonate-binding state, sulphide-binding state, organic-binding state, and residue state. In general, heavy metal elements in water-soluble, ion-exchange, and carbonate-binding states can be easily dissolved in the environment. The sum of these three states is the potential eluvial state of the element, and the value of the set of three states determine the migration degree of the element. Thus, heavy metals in water can be hydrolysed to form hydroxides, sulphides, or carbonates with their corresponding anions, and a precipitation-dissolution equilibrium is eventually reached.

The adsorption of heavy metals by colloidal substances (clay minerals, inorganic polymers such as water and oxides, organic polymers such as humus) in natural water has an important effect on the conversion of heavy metals in the groundwater environment. Adsorption is the main means by which heavy metals are transferred from an unsaturated solution to the solid phase. In the natural state, the amount of heavy metals is very low in the aqueous phase, whereas the main enrichment and solid phase are largely related to colloid adsorption. Clay 


\begin{tabular}{|l|l|l|l|l|l|l|l|}
\hline \multirow{2}{*}{ Sample } & \multicolumn{9}{|l}{ Mineral composition and content (\%) } \\
\cline { 2 - 9 } Quartz & Feldspar & Calcspar & Chlorite & Kaolinite & White mica & I/S \\
\hline A & 12 & 8 & 7 & 5 & - & - & 68 \\
\hline A $200{ }^{\circ} \mathrm{C}$ & 13 & 7 & 5 & 2 & - & 10 & 63 \\
\hline A $350{ }^{\circ} \mathrm{C}$ & 11 & 7 & 6 & 6 & - & 7 & 63 \\
\hline A $500{ }^{\circ} \mathrm{C}$ & 13 & 8 & 1 & 6 & - & 15 & 58 \\
\hline B & 5 & 5 & 8 & 10 & - & 5 & 67 \\
\hline B $200{ }^{\circ} \mathrm{C}$ & 4 & 9 & 12 & 4 & - & 8 & 67 \\
\hline B $350{ }^{\circ} \mathrm{C}$ & 4 & 6 & 6 & 3 & - & 10 & 71 \\
\hline B 500 ${ }^{\circ} \mathrm{C}$ & 5 & 12 & 8 & 2 & - & 13 & 60 \\
\hline C & 3 & - & 8 & 8 & - & 4 & 77 \\
\hline C $200{ }^{\circ} \mathrm{C}$ & 3 & - & 8 & 8 & - & 4 & 77 \\
\hline C $350{ }^{\circ} \mathrm{C}$ & 4 & 3 & 9 & 4 & - & 8 & 72 \\
\hline C $500{ }^{\circ} \mathrm{C}$ & 4 & 3 & 13 & 4 & - & 18 & 68 \\
\hline D & 5 & 4 & - & 2 & 10 & - & 79 \\
\hline D $200{ }^{\circ} \mathrm{C}$ & 6 & 3 & 1 & 3 & 12 & - & 75 \\
\hline D $350{ }^{\circ} \mathrm{C}$ & 5 & 1 & 1 & 3 & 7 & 1 & 82 \\
\hline D $500{ }^{\circ} \mathrm{C}$ & 6 & 2 & - & 2 & 8 & 8 & 74 \\
\hline E & 4 & - & 12 & 6 & - & - & 78 \\
\hline E $200{ }^{\circ} \mathrm{C}$ & 8 & 5 & 10 & 6 & - & - & 71 \\
\hline E $350{ }^{\circ} \mathrm{C}$ & 5 & 1 & 11 & 5 & - & - & 78 \\
\hline E $500{ }^{\circ} \mathrm{C}$ & 4 & 2 & 12 & 4 & - & - & 78 \\
\hline
\end{tabular}

Table 1. Mineralogical composition of five samples based on X-ray diffraction (XRD) analysis. I/S illite/ montmorillonite mix.

minerals are the most important and complex components of inorganic colloids in the environment. They are formed during the weathering process of primary minerals and consist of aluminosilicates. Oil shale contains numerous clay minerals such as montmorillonite, illite, and kaolinite, which strongly adsorb heavy metals.

In water, lead mainly exists as $\mathrm{Pb}^{2+}$, and its content and form are clearly affected by $\mathrm{CO}_{3}{ }^{2-}, \mathrm{OH}^{-}$, and $\mathrm{Cl}^{-}$, etc. Lead can exist in various forms, such as $\mathrm{PbOH}^{+}, \mathrm{Pb}(\mathrm{OH})_{2}, \mathrm{~PB}(\mathrm{OH})_{3}{ }^{-}, \mathrm{PbCl}^{+}$, and $\mathrm{PbCl}_{2}$.

The major dissolution and complexation equilibria of lead compounds are as follows ${ }^{36}$.

Solubility equilibrium:

$$
\begin{aligned}
& \mathrm{PbCO}_{3}=\mathrm{Pb}^{2+}+\mathrm{CO}_{3}^{2-} \\
& \mathrm{Pb}(\mathrm{OH})_{2}=\mathrm{Pb}^{2+}+2 \mathrm{OH}^{-} \\
& \mathrm{PbSO}_{3}=\mathrm{Pb}^{2+}+\mathrm{SO}_{4}^{2-} \\
& \mathrm{Pb}_{3}(\mathrm{OH})_{2} \cdot\left(\mathrm{CO}_{3}\right)_{2}=3 \mathrm{~Pb}^{2+}+2 \mathrm{OH}^{-}+2 \mathrm{CO}_{3}^{2-}
\end{aligned}
$$

Complex balance:

$$
\begin{aligned}
& \mathrm{Pb}^{2+}+\mathrm{OH}^{-}=\mathrm{Pb}(\mathrm{OH})^{+} \\
& \mathrm{Pb}^{2+}+2 \mathrm{OH}^{-}=\mathrm{Pb}(\mathrm{OH})_{2} \\
& \mathrm{~Pb}^{2+}+3 \mathrm{OH}^{-}=\mathrm{Pb}(\mathrm{OH})_{3}^{-} \\
& \mathrm{Pb}^{2+}+\mathrm{Cl}^{-}=\mathrm{PbCl}^{+} \\
& \mathrm{Pb}^{2+}+2 \mathrm{Cl}^{-}=\mathrm{PbCl}_{2}
\end{aligned}
$$

Benzene series content. Figure 4 shows that the concentration of benzene and toluene in each region first increased and then decreased over time, showing the same overall trend. The benzene series was not detected in the water of sample A for the first 5 days and began to appear on approximately day 6 , reaching a peak of more than $1 \mathrm{mg} / \mathrm{L}$ on day 15 . At $350{ }^{\circ} \mathrm{C}$, the peak value of benzene series was higher than $1.3 \mathrm{mg} / \mathrm{L}$. Over days 15-180, the concentration only slightly changed and decreased, indicating that the benzene series in water began to decay naturally. The final concentration of benzene series in water was less than the initial concentration. The benzene series in sample B began to appear in the water at around 3 days, reaching a peak of more than $0.9 \mathrm{mg} / \mathrm{L}$ on day 30 . At $500{ }^{\circ} \mathrm{C}$, the peak value of benzene series was above $1.7 \mathrm{mg} / \mathrm{L}$. Over days $30-60$, the concentration slightly changed and then decreased, indicating that the benzene series in water began to decay naturally. The final concentration of benzene series in water was less than the initial concentration. The benzene series 

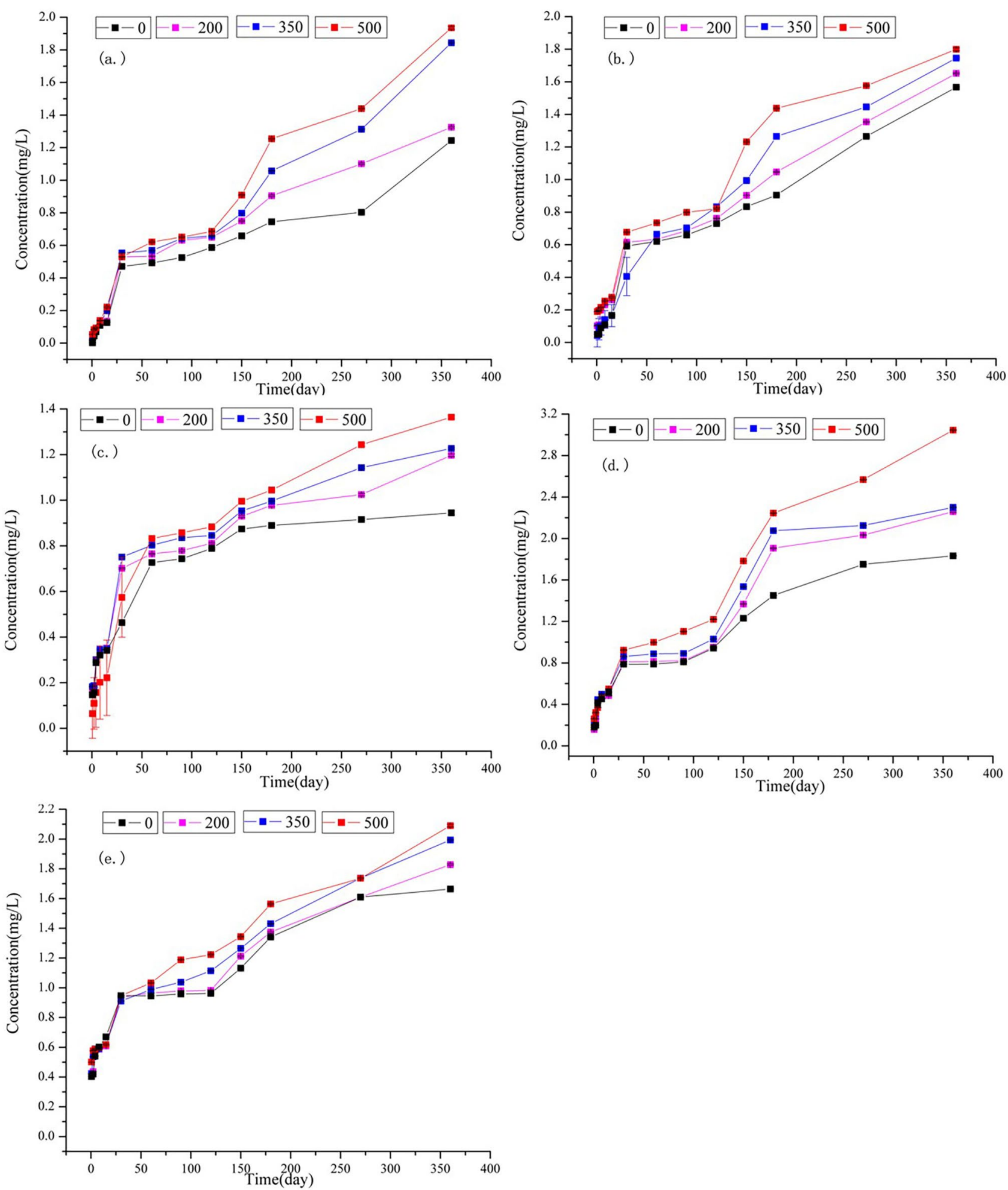

Figure 3. Change in $\mathrm{Pb}$ concentration over time in the five samples.

in sample $\mathrm{C}$ began to appear in the water at around 6 days, reaching a peak of more than $0.9 \mathrm{mg} / \mathrm{L}$ on day 15 . At $350{ }^{\circ} \mathrm{C}$, the peak value of benzene series was above $1.4 \mathrm{mg} / \mathrm{L}$. Over days $15-180$, the concentration slightly changed and then decreased, indicating that the benzene series in water began to decay naturally. The final concentration of the benzene series in water was less than the initial concentration. The benzene series in sample $\mathrm{E}$ began to appear in the water at around 6 days, reaching a peak of more than $1.5 \mathrm{mg} / \mathrm{L}$ on day 15 . At $500{ }^{\circ} \mathrm{C}$, the peak value of the benzene series was above $1.9 \mathrm{mg} / \mathrm{L}$. Over days 30-180, the concentration slightly changed and then decreased, indicating that the benzene series in water began to decay naturally. The final concentration of 

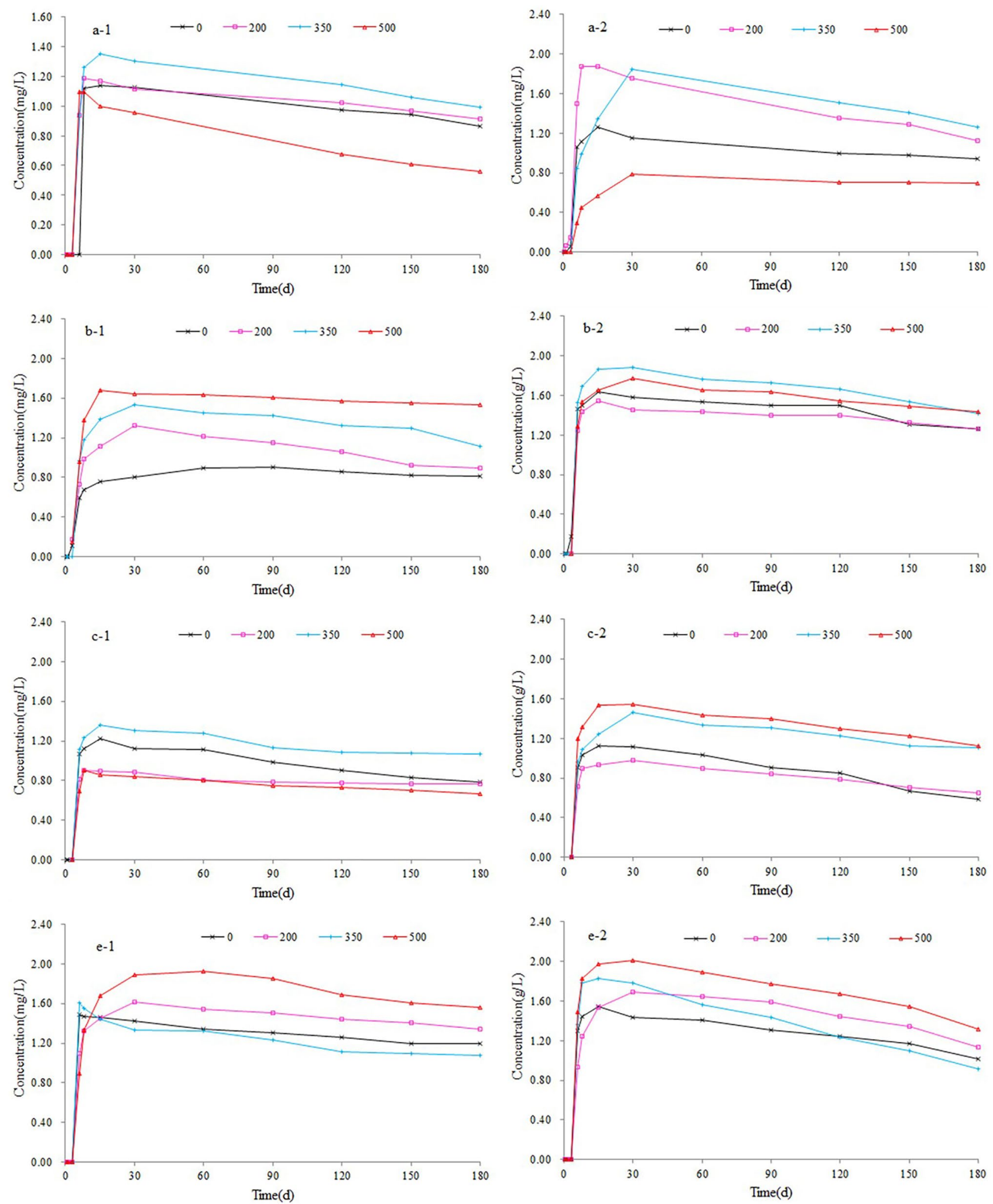

Figure 4. Change in the benzene series concentration over time in the four samples, where -1 indicates benzene and -2 indicates toluene. 
the benzene series in water was less than the initial concentration. The initial concentration of the benzene series was related to kerogen content in oil shale.

The results showed that the benzene series underwent natural attenuation in the aquifer, which occurred through a series of complex mechanisms such as dilution, volatiles, convection, dispersion, adsorption, and analysis and involved microorganisms ${ }^{37,38}$. As the concentration of each contaminated component decreased, the diffusion velocity also decreased. The contribution of various mechanisms to the natural decay of benzene series varies. Important roles include the dilution effect, volatilization, adsorption analysis, and microbial degradation.

In this study, the dilution effect and volatilization were not considered because the experiment was performed in a polyethylene terephthalate bottle filled with water. Adsorption is an important factor in the attenuation of benzene series in aquifers as nonpolar organics, such as benzene, and are easily adsorbed by organic matter on the mineral surface ${ }^{39}$. The adsorbed amount of organic matter in the mineral medium depends on the content of organic carbon, and the adsorption amount increases with increasing organic carbon contents ${ }^{40}$. After soaking for a long period, colony formation and microbial action were observed in the soaking bottle ${ }^{41-43}$. Thus, biodegradation is an important environmental process in the decomposition of benzene series.

As shown in Fig. 4, benzene and toluene first increased over time, and then decreased after reaching their maximum values. The natural decay of benzene series conformed to first-order reaction kinetics with the following equation:

$$
\mathrm{C}=\mathrm{C}_{0} \cdot \mathrm{e}^{-\lambda \mathrm{t}}
$$

where $\mathrm{C}$ is the concentration of material removed by natural attenuation at time $\mathrm{t} ; \mathrm{C}_{0}$ is the initial concentration, $\lambda$ is the material attenuation coefficient, and the unit is the inverse of time. A larger $\lambda$ indicates a faster decay rate.

Figure 5 shows the first-order kinetic equation of benzene and toluene in the natural decay process and that of benzene and toluene in the natural decay of crude oil shale rocks and residues following pyrolysis at different temperatures. Table 2 shows the determination coefficients (R2) for Fig. 5.

\section{Conclusion}

In this study, clay minerals (Aemon mixers) were the predominant inorganic minerals in all five samples, followed by quartz and carbonate minerals and a small amount of pyrite. The pyrolysis temperature affected the composition of solid oil shale residue. The XRD data showed that the clay minerals lost water with increasing pyrolysis temperature. The overall trend of the heavy metal ion $\mathrm{Pb}$ was consistent, increasing gradually over time and with increasing pyrolysis temperatures. This is because the weight loss of oil shale differs at different temperatures, leading to an increased number of heavy metal ions per unit weight. Based on the long-term water-rock interaction, the adsorption of clay minerals reached a dissolution-complexation equilibrium. After 360 days of water-rock interaction (Fig. 3), the rate of increase in the heavy metal concentration slowed, and the concentration of each sample was $>1.4 \mathrm{mg} / \mathrm{L}$ (one sample reached $3.0 \mathrm{mg} / \mathrm{L}$ ). According to the General Administration of Quality Supervision, Inspection \& Quarantine of China Standards for groundwater quality (GB/T 14848-2017), in situ transformation will result in a $\mathrm{Pb}$ content of over tenfold the standard value. Semi-coke present after oil shale in situ transformation will lead to continuous heavy metal pollution of the groundwater environment. The contents of heavy metal elements in solution are affected by the dissolution equilibrium. The concentrations of benzene and toluene in each sample increased first and then decreased over time, showing the same overall trend. These concentrations at $350^{\circ} \mathrm{C}$ and $500{ }^{\circ} \mathrm{C}$ were highest in the four regions after pyrolysis. The benzene concentration of each sample was $>1 \mathrm{~g} / \mathrm{L}$ (one sample reached $1.9 \mathrm{~g} / \mathrm{L}$ ), whereas the toluene concentration of each sample was $>1.5 \mathrm{~g} / \mathrm{L}$ (one sample reaches $2.0 \mathrm{~g} / \mathrm{L}$ ). According to the General Administration of Quality Supervision, Inspection \& Quarantine of China Standards (GB/T 14848-2017), in situ transformation will result in concentrations of benzene and toluene that are $10^{4}$ - and 1070-fold over the standard limit. The concentration of benzene series was affected by adsorption and microbial degradation, and the attenuation rate of benzene was lower than that of toluene. Oil shale is currently being tested in the field, and a solution for heavy metal pollution must be developed. 

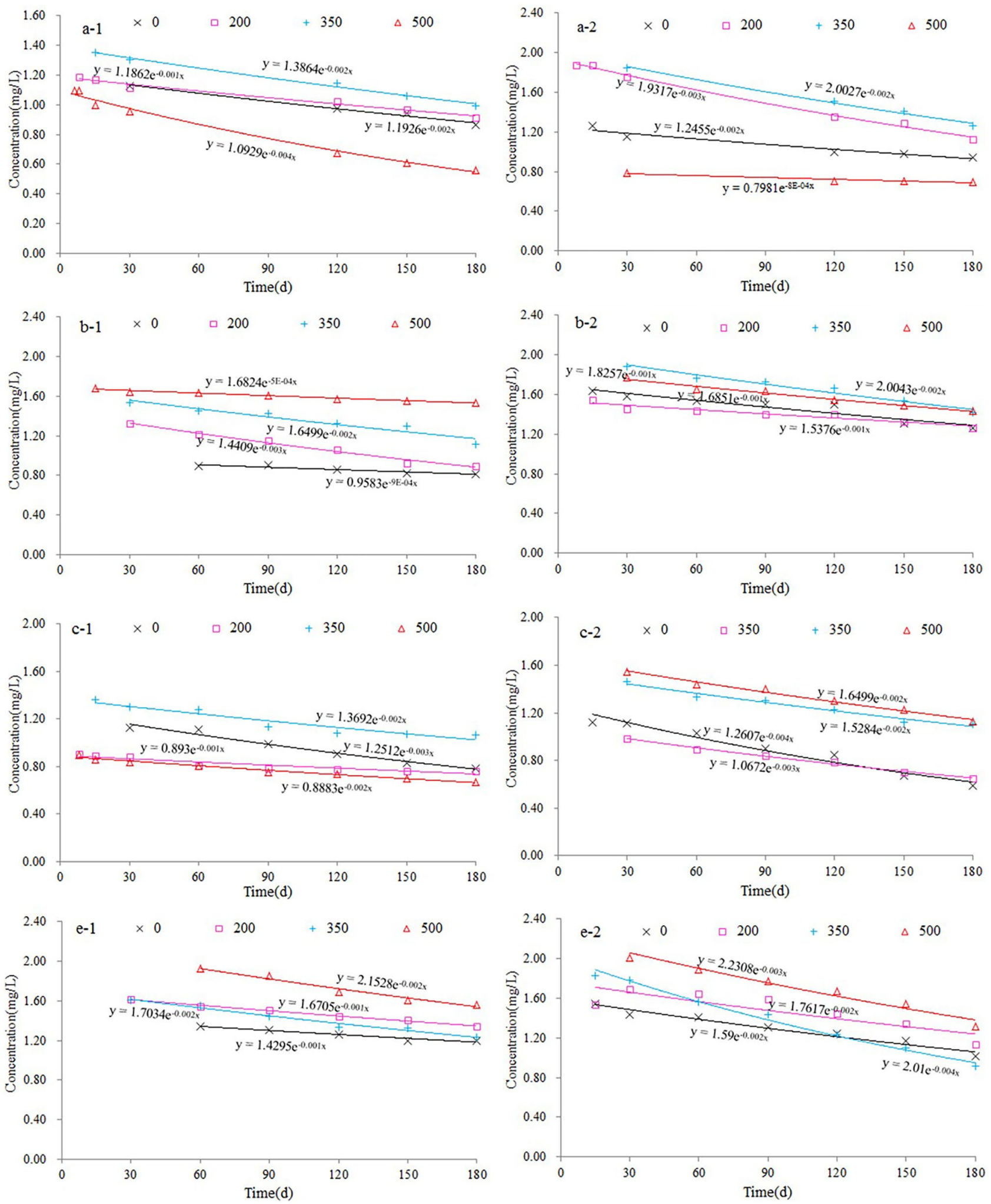

Figure 5. First-order decay kinetic equation of benzene and toluene. 


\begin{tabular}{|l|l|l|}
\hline & $\mathbf{R}^{2}$-Benzene & $\mathbf{R}^{2}$-Toluene \\
\hline A-0 & 0.9789 & 0.9489 \\
\hline A-200 & 0.983 & 0.9936 \\
\hline A-350 & 0.9903 & 0.9849 \\
\hline A-500 & 0.991 & 0.8959 \\
\hline B-0 & 0.8885 & 0.897 \\
\hline B-200 & 0.9775 & 0.9232 \\
\hline B-350 & 0.9153 & 0.9589 \\
\hline B-500 & 0.9743 & 0.9819 \\
\hline C-0 & 0.9759 & 0.96 \\
\hline C-200 & 0.8525 & 0.993 \\
\hline C-350 & 0.9011 & 0.9709 \\
\hline C-500 & 0.9805 & 0.9841 \\
\hline E-0 & 0.9537 & 0.9603 \\
\hline E-200 & 0.9932 & 0.7485 \\
\hline E-350 & 0.9722 & 0.9892 \\
\hline E-500 & 0.963 & 0.9556 \\
\hline
\end{tabular}

Table 2. The determination coefficients $\left(\mathrm{R}^{2}\right)$ for the regression of samples.

Received: 18 December 2020; Accepted: 27 July 2021

Published online: 09 August 2021

\section{References}

1. Hu, S., Xiao, C., Jiang, X. \& Liang, X. Potential impact of in-situ oil shale exploitation on aquifer system. Water https://doi.org/10. 3390/w10050649 (2018).

2. Song, X., Zhang, C., Shi, Y. \& Li, G. Production performance of oil shale in-situ conversion with multilateral wells. Energy https:// doi.org/10.1016/j.energy.2019.116145 (2019).

3. Sun, Y., Liu, Z., Li, Q., Deng, S. \& Guo, W. Controlling groundwater infiltration by gas flooding for oil shale in situ pyrolysis exploitation. J. Petrol. Sci. Eng. 179, 444-454. https://doi.org/10.1016/j.petrol.2019.04.055 (2019).

4. Yang, X. et al. Research and economic analysis of the source-load coordination of oil shale exploitation. Math. Probl. Eng. 1-14, 2019. https://doi.org/10.1155/2019/4897156 (2019).

5. Martins, M. F., Salvador, S., Thovert, J.-F. \& Debenest, G. Co-current combustion of oil shale-Part 1: Characterization of the solid and gaseous products. Fuel 89, 144-151 (2010).

6. Wang, J. X., Sun, P. C., Liu, Z. J., Li, L. \& Chen, Z. Depositional environmental controls on the genesis and characteristics of oil shale: Case study of the Middle Jurassic Shimengou Formation, northern Qaidam Basin, north-west China. Geol. J. 55, 4585-4603. https://doi.org/10.1002/gj.3688 (2019).

7. Pan, S. et al. Molecular structure and electronic properties of oil shale kerogen: An experimental and molecular modeling study. Energy Fuels 32, 12394-12404. https://doi.org/10.1021/acs.energyfuels.8b03307 (2018).

8. Han, X., Kulaots, I., Jiang, X. \& Suuberg, E. M. Review of oil shale semicoke and its combustion utilization. Fuel 126, 143-161. https://doi.org/10.1016/j.fuel.2014.02.045 (2014).

9. Maguire-Boyle, S. J. \& Barron, A. R. Organic compounds in produced waters from shale gas wells. Environ. Sci. Process Impacts 16, 2237-2248. https://doi.org/10.1039/c4em00376d (2014).

10. Alley, B., Beebe, A., Rodgers, J. \& Castle, J. W. Chemical and physical characterization of produced waters from conventional and unconventional fossil fuel resources. Chemosphere 85, 74-82. https://doi.org/10.1016/j.chemosphere.2011.05.043 (2011).

11. Khan, N. A. et al. Volatile-organic molecular characterization of shale-oil produced water from the Permian Basin. Chemosphere 148, 126-136. https://doi.org/10.1016/j.chemosphere.2015.12.116 (2016).

12. Yu, F., Sun, P., Zhao, K. A., Ma, L. \& Tian, X. Experimental constraints on the evolution of organic matter in oil shales during heating: Implications for enhanced in situ oil recovery from oil shales. Fuel https://doi.org/10.1016/j.fuel.2019.116412 (2020).

13. Jaber, J. O. \& Probert, S. D. Environmental-impact assessment for the proposed oil-shale integrated tri-generation plant. Appl. Energy 62, 169-209. https://doi.org/10.1016/S0306-2619(99)00006-9 (1999).

14. Gross, S. A. et al. Analysis of BTEX groundwater concentrations from surface spills associated with hydraulic fracturing operations. J. Air Waste Manag. Assoc. 63, 424-432 (2013).

15. Arthur, M. A. \& Cole, D. R. Unconventional hydrocarbon resources: Prospects and problems. Elements 10, 257-264 (2014),

16. Nelson, K. et al. The effect of an in situ-produced oil shale processing water on metabolism. Arch. Environ. Contam. Toxicol. 7, 273-281 (1978).

17. Jefimova, J., Irha, N., Reinik, J., Kirso, U. \& Steinnes, E. Leaching of polycyclic aromatic hydrocarbons from oil shale processing waste deposit: A long-term field study. Sci. Total Environ. 481, 605-610. https://doi.org/10.1016/.jscitotenv.2014.02.105 (2014).

18. Jefimova, J. et al. Leachability of trace elements from the aged and fresh spent shale deposit-A field study. Oil Shale https://doi. org/10.3176/oil.2013.3.06 (2013).

19. Hu, S., Xiao, C., Liang, X., Cao, Y., Wang, X. \& Li, M. The influence of oil shale in situ mining on groundwater environment: A water-rock interaction study. Chemosphere 228 384-389. https://doi.org/10.1016/j.chemosphere.2019.04.142(2019).

20. Jiang, X., Han, X. \& Cui, Z. Mechanism and mathematical model of Huadian oil shale pyrolysis. J. Therm. Anal. Calorim. 86, 457-462 (2006).

21. Kök, M. \& Pamir, M. Non-isothermal pyrolysis and kinetics of oil shales. J. Therm. Anal. Calorim. 56, 953-958 (1999).

22. Liu, Q., Han, X., Li, Q., Huang, Y. \& Jiang, X. TG-DSC analysis of pyrolysis process of two Chinese oil shales. J. Therm. Anal. Calorim. 116, 511-517 (2014).

23. Janković, B. The kinetic modeling of the non-isothermal pyrolysis of Brazilian oil shale: Application of the Weibull probability mixture model. J. Petrol. Sci. Eng. 111, 25-36 (2013). 
24. Bai, F., Sun, Y., Liu, Y., Li, Q. \& Guo, M. Thermal and kinetic characteristics of pyrolysis and combustion of three oil shales. Energy Convers. Manage. 97, 374-381 (2015).

25. Riley, R. G., Garland, T. R., Shiosaki, K., Mann, D. C. \& Wildung, R. E. Alkylpyridines in surface waters, groundwaters, and subsoils of a drainage located adjacent to an oil shale facility. Environ. Sci. Technol. 15, 697-701 (1981).

26. Li, Z., Ma, Z., van der Kuijp, T. J., Yuan, Z. \& Huang, L. A review of soil heavy metal pollution from mines in China: Pollution and health risk assessment. Sci. Total Environ. 468-469, 843-853. https://doi.org/10.1016/j.scitotenv.2013.08.090 (2014).

27. Baizhong, Y., Qiu, S., Xiao, C. \& Liang, X. Characteristics of Mineral fluids and geothermal reservoir in Changbai Mountain, Northeast of China. Geochem. Int. 57, 83-97. https://doi.org/10.1134/s0016702919010038 (2019).

28. Na, J. G., Im, C. H., Chung, S. H. \& Lee, K. B. Effect of oil shale retorting temperature on shale oil yield and properties. Fuel 95 , 131-135. https://doi.org/10.1016/j.fuel.2011.11.029 (2012).

29. Yan, J., Jiang, X. \& Han, X. Study on the characteristics of the oil shale and shale char mixture pyrolysis. Energy Fuels 23, 5792-5797 (2009).

30. Snyder, R. \& Jenkins, R. Introduction to X-ray Powder Diffractometry (Wiley-Interscience, 2012).

31. Jingru, B., Qing, W., Shuyuan, L., Chunyu, L. \& Xiaohui, G. Research on release of trace elements at retorting of huadian oil shale. Oil Shale 25. https://doi.org/10.3176/oil.2008.1.03 (2008).

32. Guo, R., Yang, J., Liu, D. \& Liu, Z. The fate of As, Pb, Cd, Cr and Mn in a coal during pyrolysis. J. Anal. Appl. Pyrol. 70, 555-562 (2003).

33. Guo, R., Yang, J. \& Liu, Z. Behavior of trace elements during pyrolysis of coal in a simulated drop-tube reactor. Fuel 83, 639-643 (2004).

34. Aunela-Tapola, L. A., Frandsen, F. J. \& Häsänen, E. K. Trace metal emissions from the Estonian oil shale fired power plant. Fuel Process. Technol. 57, 1-24 (1998).

35. Querol, X., Juan, R., Lopez-Soler, A., Fernandez-Turiel, J. \& Ruiz, C. R. Mobility of trace elements from coal and combustion wastes. Fuel 75, 821-838 (1996).

36. Fetter, C. W., Boving, T. \& Kreamer, D. Contaminant Hydrogeology (Waveland Press, 2017)

37. Flynn, R. M., Rossi, P. \& Hunkeler, D. Investigation of virus attenuation mechanisms in a fluvioglacial sand using column experiments. FEMS Microbiol. Ecol. 49, 83-95. https://doi.org/10.1016/j.femsec.2003.08.017 (2004).

38. Farhadian, M., Vachelard, C., Duchez, D. \& Larroche, C. In situ bioremediation of monoaromatic pollutants in groundwater: A review. Bioresour. Technol. 99, 5296-5308. https://doi.org/10.1016/j.biortech.2007.10.025 (2008).

39. Chiou-1984-Reply-to-comments-by-macintyre-and-.pdf. https://doi.org/10.1021/es00110a009.

40. Serrano, A. \& Gallego, M. Fullerenes as sorbent materials for benzene, toluene, ethylbenzene, and xylene isomers preconcentration. J. Sep. Sci. 29, 33-40. https://doi.org/10.1002/jssc.200500200 (2006).

41. Kao, C. \& Wang, C. Control of BTEX migration by intrinsic bioremediation at a gasoline spill site. Water Res. 34, 3413-3423 (2000).

42. Kao, C.-M. \& Borden, R. C. Site-specific variability in BTEX biodegradation under denitrifying conditions. Ground Water 35, 305 (1997).

43. Cozzarelli, I. M. et al. Progression of natural attenuation processes at a crude-oil spill site: I. Geochemical evolution of the plume. J. Contaminant Hydrol. 53, 369-385 (2001).

\title{
Acknowledgements
}

We are grateful for the help from the Jilin University staff. We thank two anonymous reviewers and associate editor for their constructive feedback.

\section{Author contributions}

H.W. and S.Q. processed the data and analysed the results; H.W. wrote the manuscript; W.Z. and X.L. reviewed the manuscript and made helpful suggestions; X.L. revised the manuscript.

\section{Funding}

The research was funded by Natural Science Foundation of China (No. 41572216), The National Natural Science Funds of China (42002260), The China Geological Survey Shenyang Geological Survey Center "Hydrogeological investigation in the Songnen Plain" project ([2019]DD20190340-W09), The Provincial School Co-construction Project Special-Leading Technology Guide (SXGJQY2017-6), and Geological Survey Foundation of Jilin Province (2018-36-13). Key research and development program of Shaanxi Province (2017ZDCXL-SF-03-01-01).

\section{Competing interests}

The authors declare no competing interests.

\section{Additional information}

Correspondence and requests for materials should be addressed to S.Q. or X.L.

Reprints and permissions information is available at www.nature.com/reprints.

Publisher's note Springer Nature remains neutral with regard to jurisdictional claims in published maps and institutional affiliations.

\begin{abstract}
(c) (i) Open Access This article is licensed under a Creative Commons Attribution 4.0 International License, which permits use, sharing, adaptation, distribution and reproduction in any medium or format, as long as you give appropriate credit to the original author(s) and the source, provide a link to the Creative Commons licence, and indicate if changes were made. The images or other third party material in this article are included in the article's Creative Commons licence, unless indicated otherwise in a credit line to the material. If material is not included in the article's Creative Commons licence and your intended use is not permitted by statutory regulation or exceeds the permitted use, you will need to obtain permission directly from the copyright holder. To view a copy of this licence, visit http://creativecommons.org/licenses/by/4.0/.
\end{abstract}

(C) The Author(s) 2021 